\title{
Modified procedure in a Socket-Shield technique in the aesthetic zone - Case report
}

Moura $H^{1}$, Machado $S^{1}$, Sousa $F^{1}$, Santos $I^{1}$, Blashkiv $O^{2}$

\section{Affiliations:}

1. Private Practice- Hélder Moura Dental Clinics

Guimarães, Portugal

2. Oleg Blashkiv Lab

Porto, Portugal

\section{Corresponding author:}

Hélder Moura

heldermoura.md@gmail.com

\section{ABSTRACT}

Purpose: After tooth extraction alveolar socket bone undergoes a remodelling process. The horizontal and the vertical bone losses complicate dental rehabilitation with implants. Socket-Shield technique maintain the periodontal attachment including cementum, periodontal ligament and bundle bone. In this report this technique was indicated to replace the lost teeth.

Case report: A Socket-Shield technique was used for immediate implant placement on a non-restorable teeth by failure of crowns in teeth 12,11 and 21 . Through a osteotomy and manipulation of soft tissues with provisionals it was possible to correct the gingival contours and zeniths.

Conclusion: Atraumatic extraction and socket preservation technique decreases the alveolar bone resorption by maintaining the hard and the soft tissue volume. Provisionalization allows management of the soft tissues around the implants. This treatment offers a predictable aesthetic and functional result .

\section{KEYWORDS}

Socket-Shield technique, atraumatic extraction, immediate Implant 


\section{INTRODUCTION}

In oral rehabilitation the challenge is considerable when it is impossible to maintain the teeth in the aesthetic zone..$^{1,2}$

In the anterior maxilla the reabsorption is centripetal because the buccal bone is thinner than the bone on the palatal side.,34 The extent of bone resorption can be up to 3.8 and $1.24 \mathrm{~mm}$ in the horizontal and vertical directions.,5 The alveolar bone resorption is a physiologic phenomenon due to the fact that the periodontal ligament is lost with its vascular supply.

Currently, rehabilitation of aesthetic areas with immediate postextractive single dental implants is a predictable procedure characterised by high survival rates in the short and long terms. ${ }^{1}$ Implants in extraction sockets were supposed to reduce the number of surgical procedures and the treatment plan time. ${ }^{7}$

The focus on treatment goals has also shifted from merely implant survival to treatment success. These include optimal aesthetic results, healthy peri-implant tissues, restoration of function, and the long-term maintenance of these. ${ }^{1,8}$

Different surgical techniques have been proposed to counteract, or at least limit, the physiologic bone resorption. Among them are partial extraction techniques, gingival grafts and guided bone regeneration. ${ }^{1,8}$

The Socket-Shield technique, which was first described by Hürzeler ${ }^{9}$, is an alternative to the conventional techniques. ${ }^{1}$

This technique consists of the sectioning and removal of the crown of the compromised, non-restorable tooth, leaving only the buccal part of the root. The periodontal ligament and associated blood vessels avoid the physiologic bone resorption of the buccal bone and therefore the contraction of the overlying soft tissue. ${ }^{1,10}$

The aim of this report is to describe a case of crown failure with implant treatment associated with a modified Socket-Shield technique in the aesthetic zone.

\section{CASE REPORT}

A 31-year-old, healthy, non-smoking female patient consulted in a private appointment with 21 horizontal fracture caused by an injury (tooth numbered by FDI World Dental Federation).

Periapical radiography revealed that 11 and 21 have a horizontal fracture of the root with no possibility to retreat with a new crown (Figure 1). Tooth 12 in orthopantomography (Figure 2), revealed maladaptation of the crown.

CBCT shows that the labial bone plate was thinner than $1 \mathrm{~mm}$ (Figure 3; Figure 4; Figure 5). The patient's periodontal ligament was healthy with no signs of inflammation and without pulpal pathologies. It was verified a type I socket ${ }^{11}$, the facial soft tissue and buccal plate of the bone show normal levels in relation to the cementoenamel junction of the pre-extracted tooth and remained intact post-extraction.

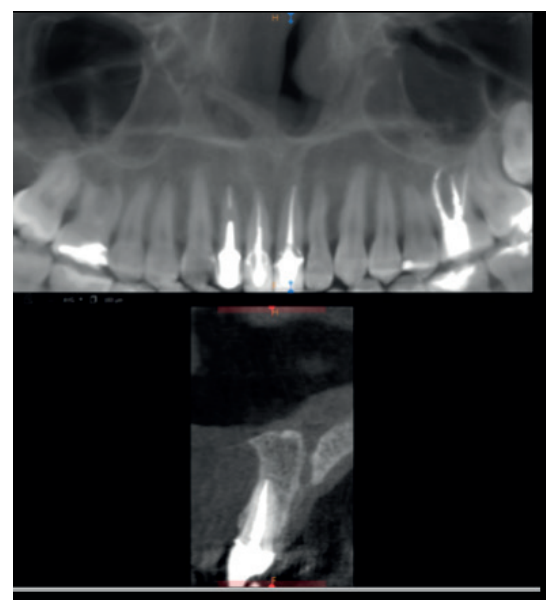

Figure 3 Initial CBCT tooth 12

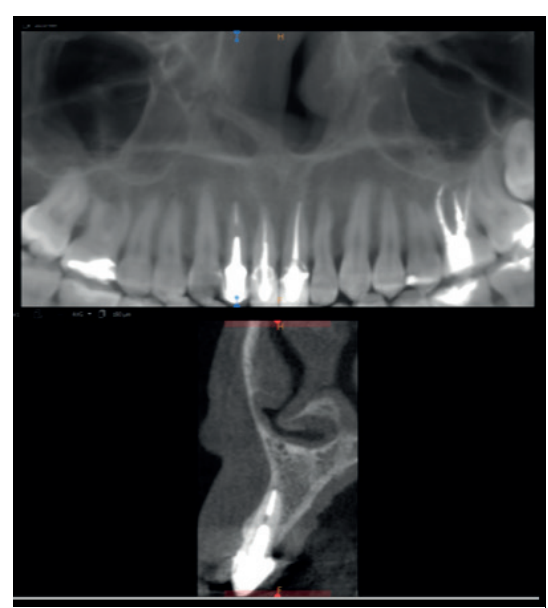

Figure 4 Initial CBCT tooth 11

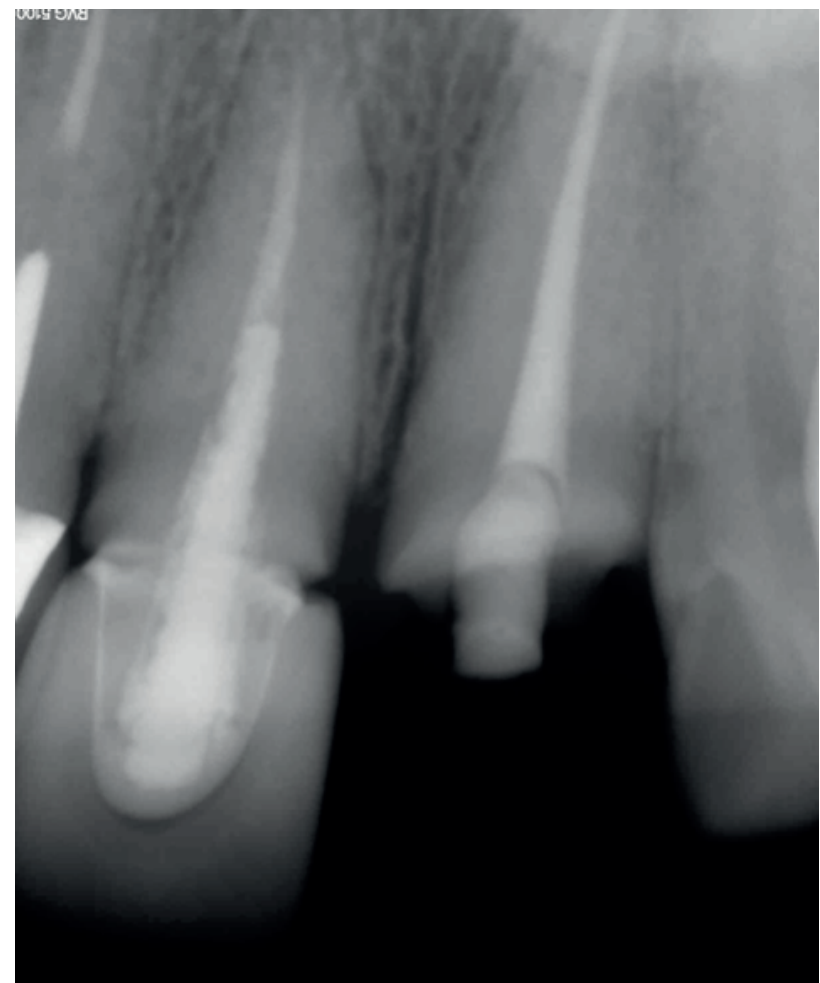

Figure 1 Initial X-ray

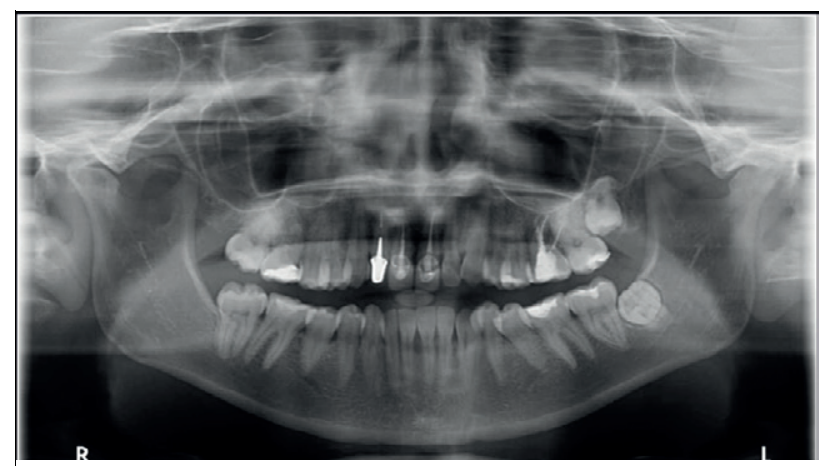

Figure 2 Initial orthopantomography

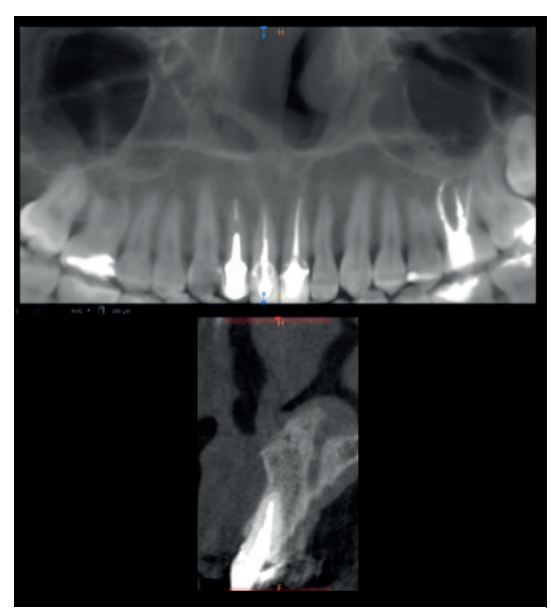

Figure 5 Initial CBCT tooth 21 
The patient has a high smile line with inflammation of the gingival contour. She also presents assimilar zenith and middle line deviation to the right which compromised the aesthetic. (Figure 6; Figure 7) Moreover, the patient had a thick gingival low scallop. ${ }^{12}$ (Figure 8; Figure 9)

Because of non-restorable asymptomatic tooth with healthy and stable buccal root, it was planned to place implants with socket-shield technique. The treatment was planned to correct the high smile, gingival contours and zeniths according to the aesthetic standards, which involves a modification in SocketShield technique. To correct the high smile line and zenith an osteotomy on the teeth $21,11,12(1 \mathrm{~mm})$ and a gengivectomy (1 $\mathrm{mm}$ ) on tooth 13 were performed. (Figure 10)

Before surgery, informed written consent was obtained from the patient for publication of this case report and its attached images. To do the asepsis of the patient it was performed a tartarectomy 3 days before surgery, mouth rinsing was done with $0.2 \%$ chlorhexidine solution and an antiseptic solution and disinfectant was applied in the operative zone.

Steps followed for Socket-Shield immediate implant:

The surgery was performed under local infiltration anesthesia (Artinibsa $(72 \mathrm{mg} / 1.8 \mathrm{ml}+0.018 \mathrm{mg} / 1.8 \mathrm{~mm})$ injectable solution Articaine + Epinephrine).

1. Root sectioning and atraumatic root extraction: The crowns were removed atraumatically with long burs. (Figure 11; Figure 12) The root was sectioned along its long axis

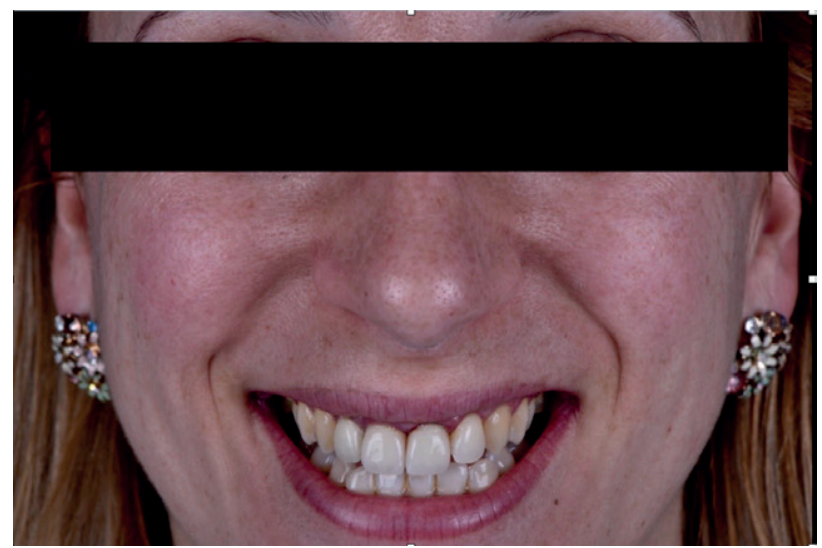

Figure 6 Initial extra-oral frontal view

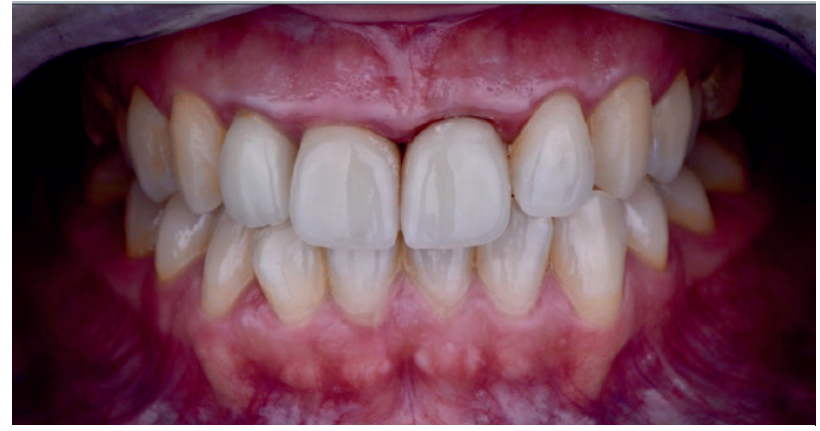

Figure 7 Initial intra-oral frontal view in occlusion

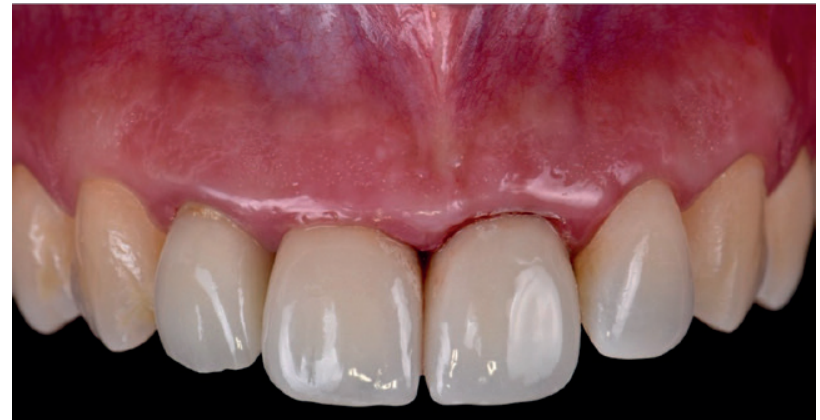

Figure 8 Initial intra-oral frontal view

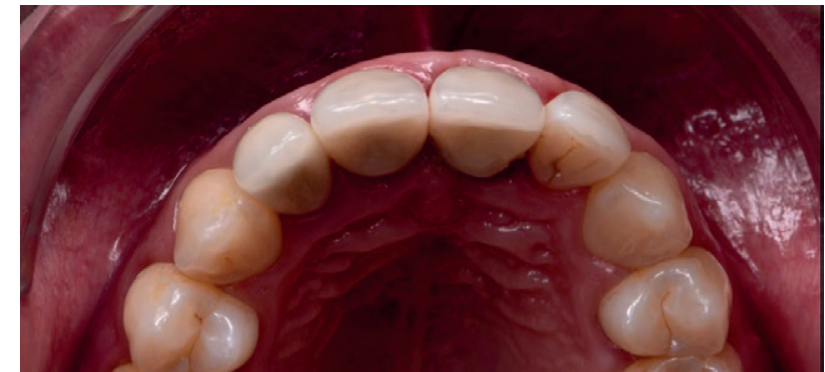

Figure 9 Initial intra-oral occlusal view

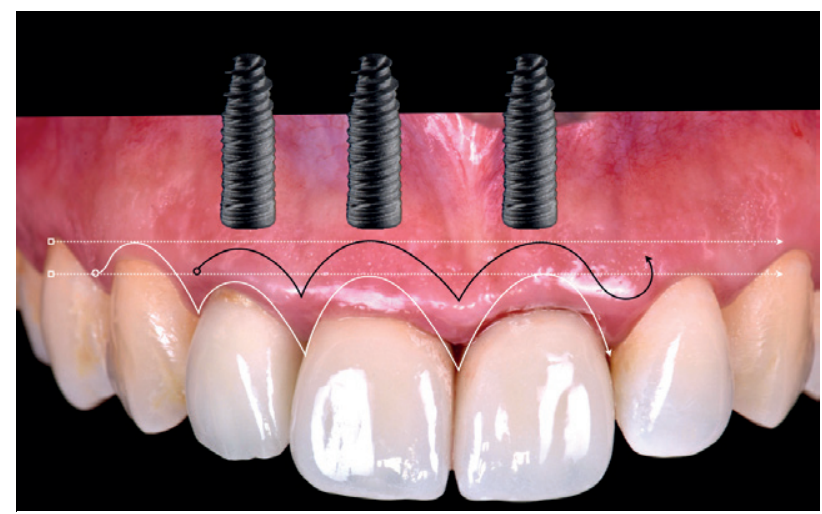

Figure 10 Treatment plan with ideal position of the gingival contour, bone crest and implants

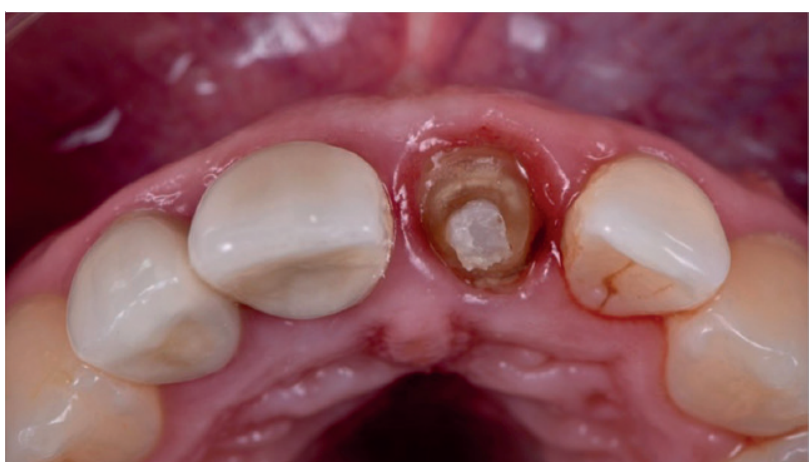

Figure 11 Surgery day occlusal view

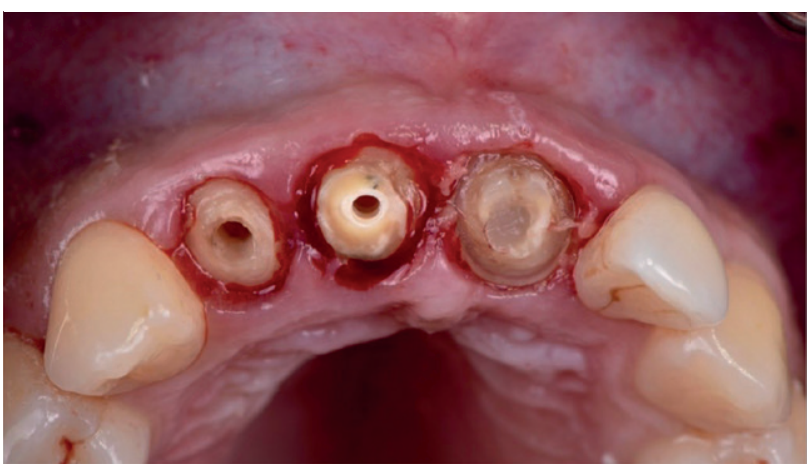

Figure 12 Surgery day: decoronate crowns

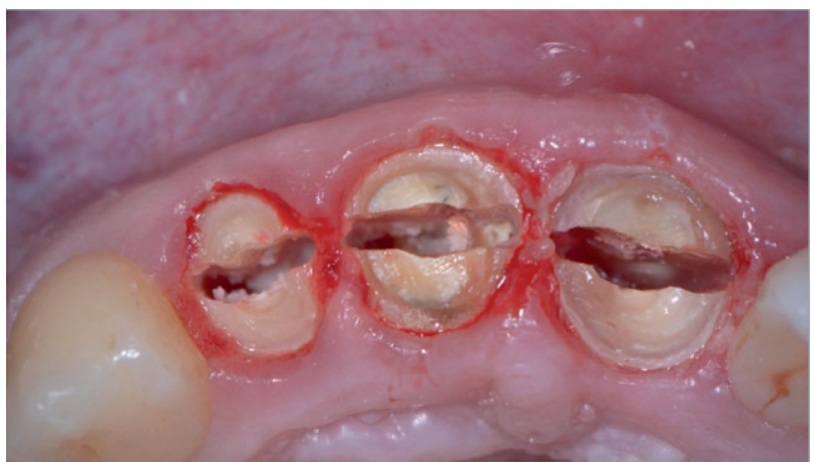

Figure 13 Surgery day: sectioned roots mesiodistally 
mesiodistally as far apical as possible. (Figure 13)The palatal portion of the residual root was extracted and the labial portion inside the alveolar socket was kept. Atraumatic extraction was done with periotomes, luxatores and forceps preserving the facial root section.

2. Socket Shield Preparation: The root fragment was bevelled and prepared with a coarse-grained diamond bur into a C-shape, $1 \mathrm{~mm}$ thick shield and at the bone level crest. The socket was then debrided slightly and irrigated with normal saline solution. An osteotomy was performed to correct the gingival smile elevating the final crowns `zenith (Figure 14; Figure 15).

3: Drilling Protocol and Implant Placement: Drilling should be done in palatal wall and not in the socket. All the osteotomy drill should be used in the same direction and depth. Final drill should not be in contact with the shield. The distance between implant and the shield should be kept purposefully to fill with bone graft material.

Implant bed preparation was drilled step by step in the alveolar socket, and a Biotech System * Indexing implant (diameter $3.6 \mathrm{~mm}$; height $10 \mathrm{~mm}$ ) with platform switching was placed in the alveolar socket which had been shown to minimize marginal bone loss. ${ }^{10}$ The cover screw was then installed on the implant.

4. Bone Grafting: The gap between the implant and the SocketShield was filled with spongious bone substitute granules ( 0.25 $\mathrm{mm}-1 \mathrm{~mm} / 0.5 \mathrm{~g}$ Bio-Oss ${ }^{\circ}$ Geistlich). ${ }^{13}$ (Figure 16)

The surgical area was then sutured (nylon aragó nonreabsorble 6/0) with horizontal internal sutures and suspension sutures, just to avoid the collapse of the soft tissues due to the osteotomy (Figure 17; Figure 18).

5. Temporization: It was used a structure bonded on the adjacent tooth out of occlusion as a provisional leaving space to healing and tissue maturation. ${ }^{13}$ (Figure 19)

6. Postoperative instructions and care: Liquid diet for three days and soft diet for three weeks. Antibiotics (amoxicilin and clavulanate $875+125 \mathrm{mg}$ ) for seven days; Ibuprofen $600 \mathrm{mg}$ for 3 days; $1.88202 \%$ chlorhexidine gel for 14 days. Avoid biting,

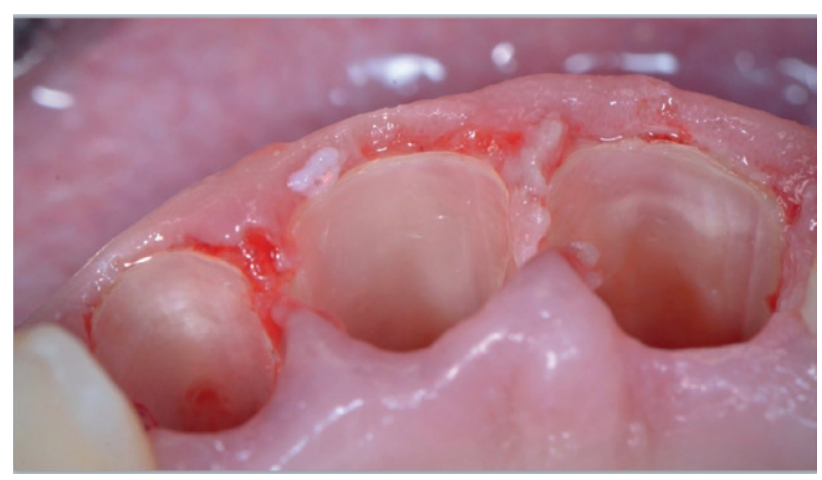

Figure 14 Surgery day: C-shape shields

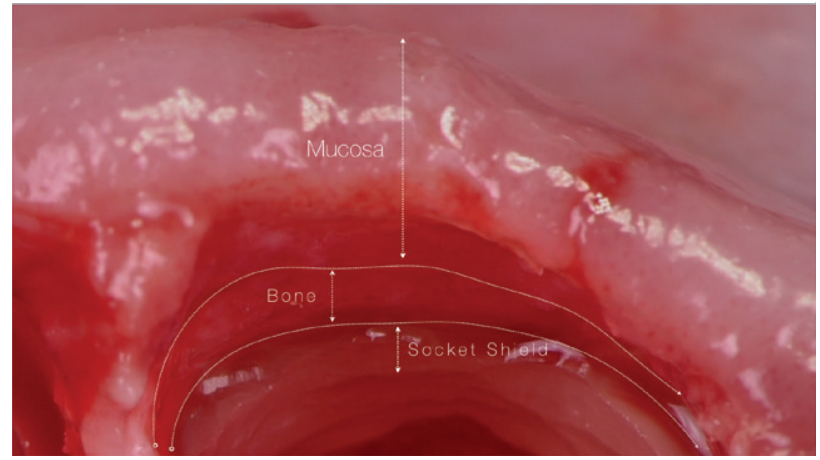

Figure 15 Reduction of the shield and osteotomy

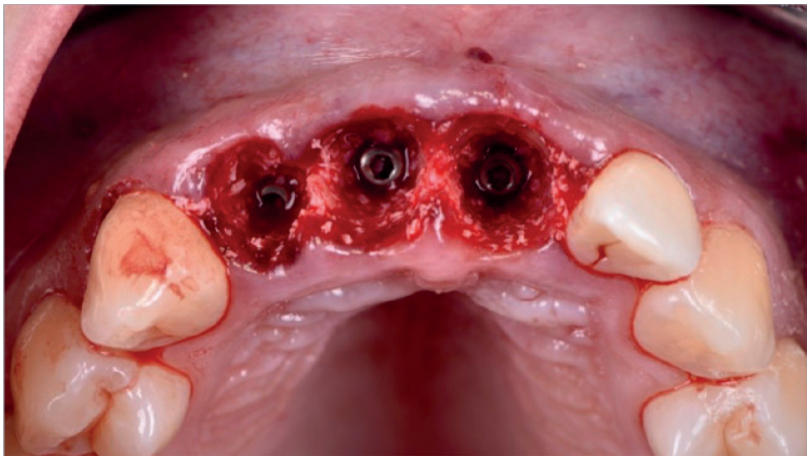

Figure 16 Surgery day: Implant placement and gap filling

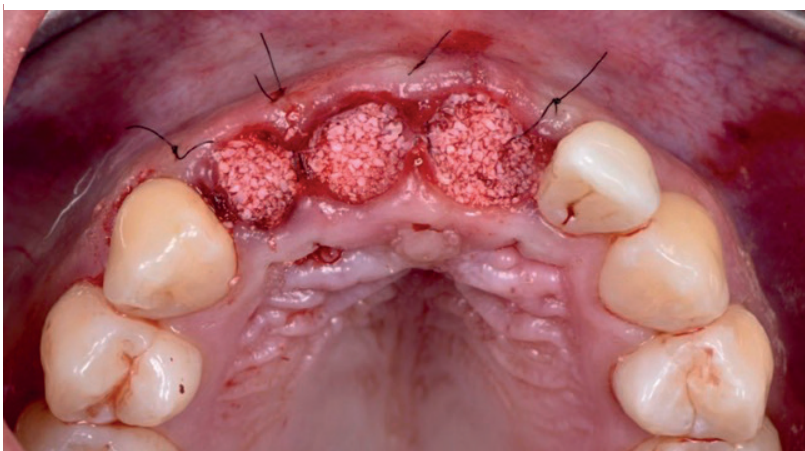

Figure 17 Surgery day: Horizontal sutures

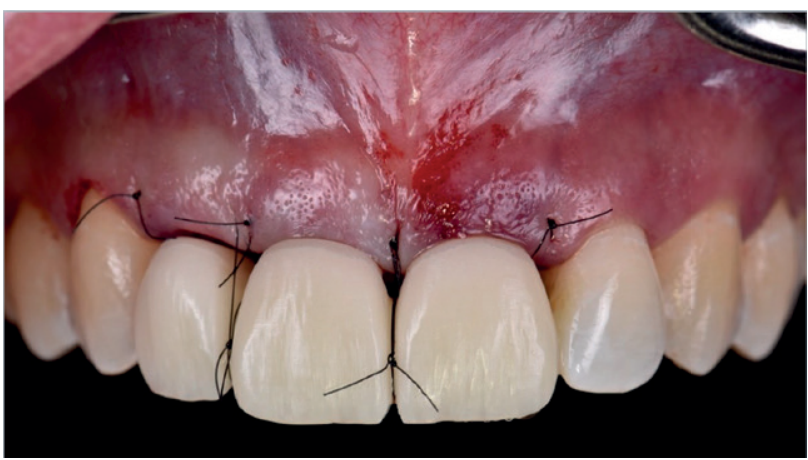

Figure 18 Surgery day: structure bonded on the adjacent tooth and suspension sutures

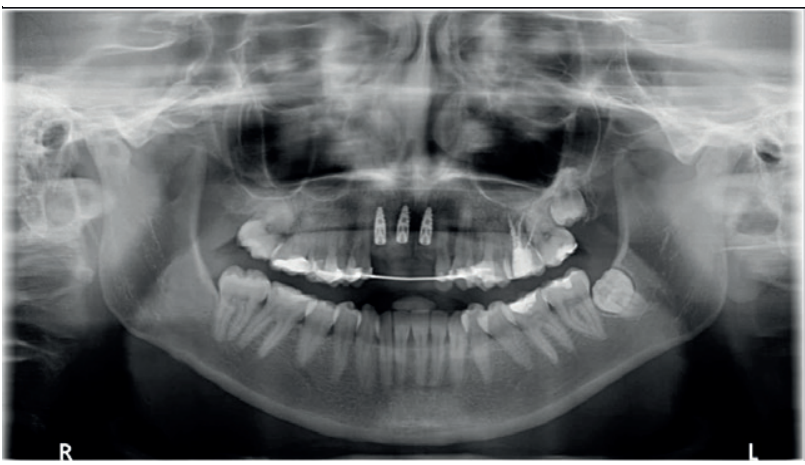

Figure 19 Surgery day: orthopantomography 
smoking, sucking liquid with straw. Apply ice packs over face.

The patient was asked to attended follow up visits after 2 and 6 days (Figure 20, 21), 1 and 3 months (Figure 22, 23). Clinical examination indicated that no inflammation was present.

The second surgery was done four months later. Cone beam computed tomography (CBCT) scanning indicated stable hard tissue around the implants (Figure 24).

Through a flapless technique a diamond spherical drill was used

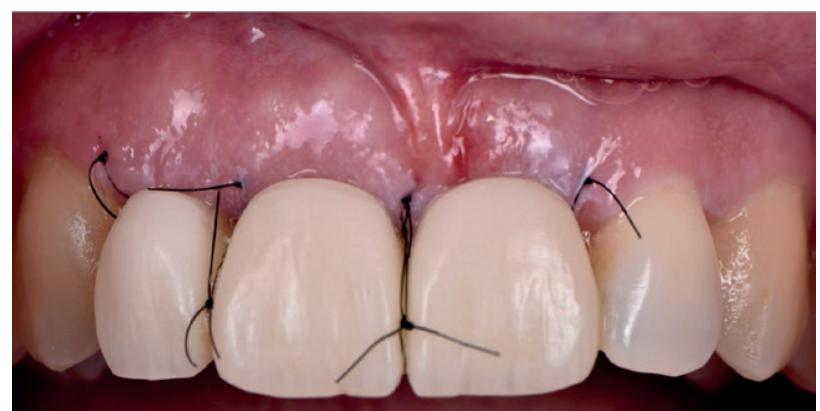

Figure 20 Follow up two days after the surgery

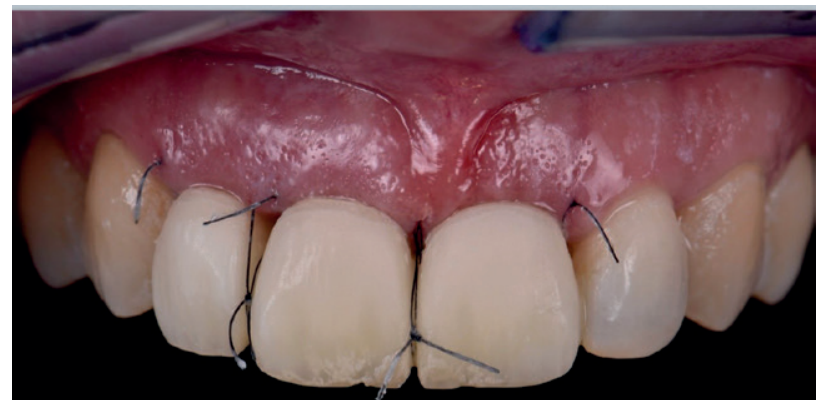

Figure 21 Follow up six days after the surgery

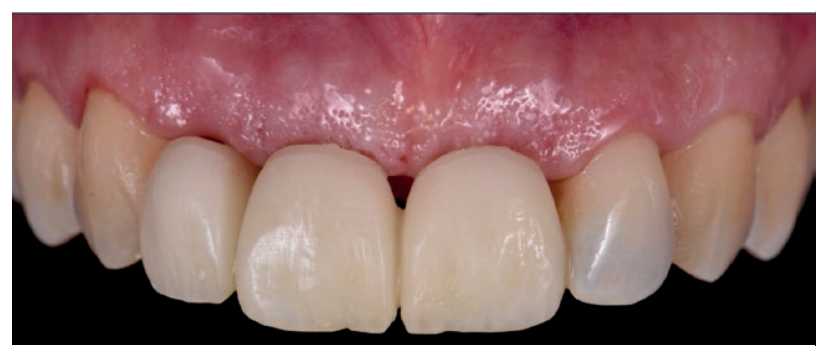

Figure 22 Follow-up one month later

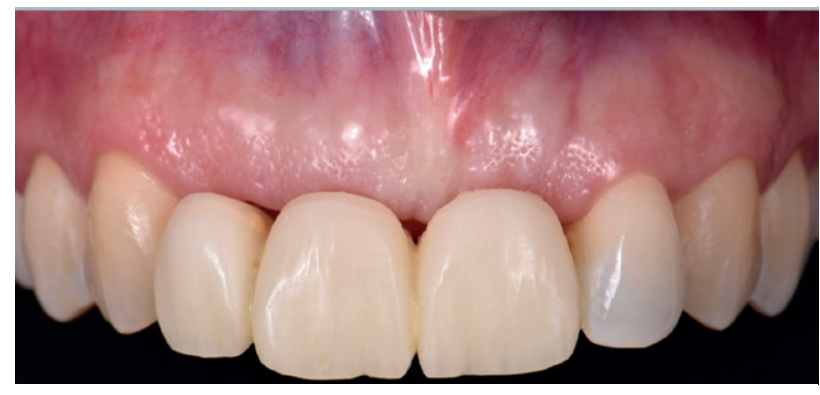

Figure 23 Follow-up three months later

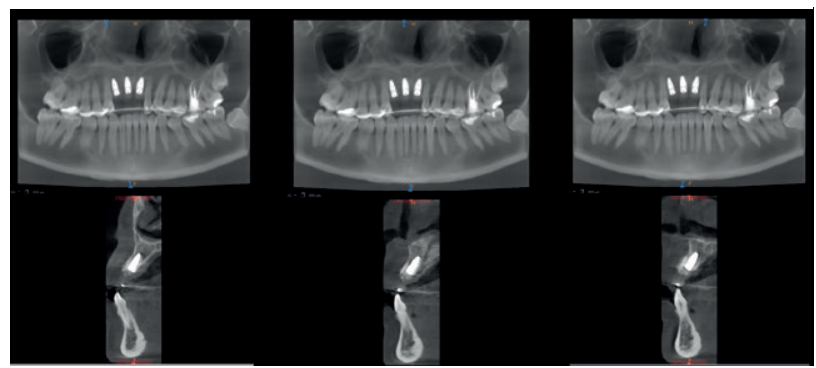

Figure $24 \mathrm{CBCT}$ : Follow-up four months late to access the implant and remove the cover screw. An impression was done to the first provisionals in order to manage the soft

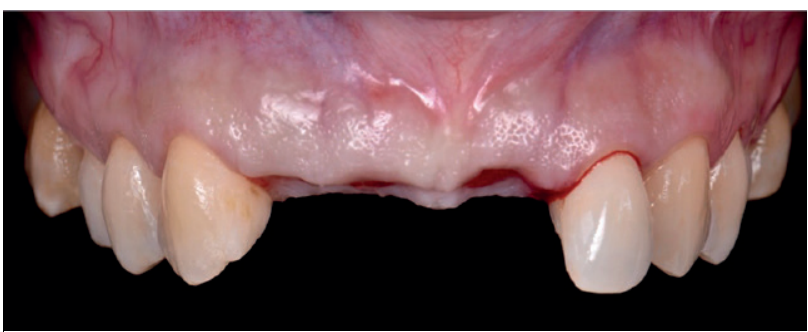

Figure 25 Follow up four months later

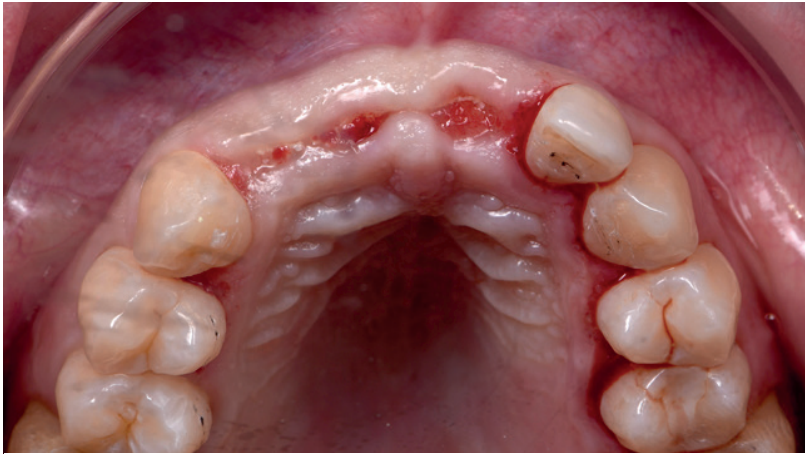

Figure 26 Follow up four months later

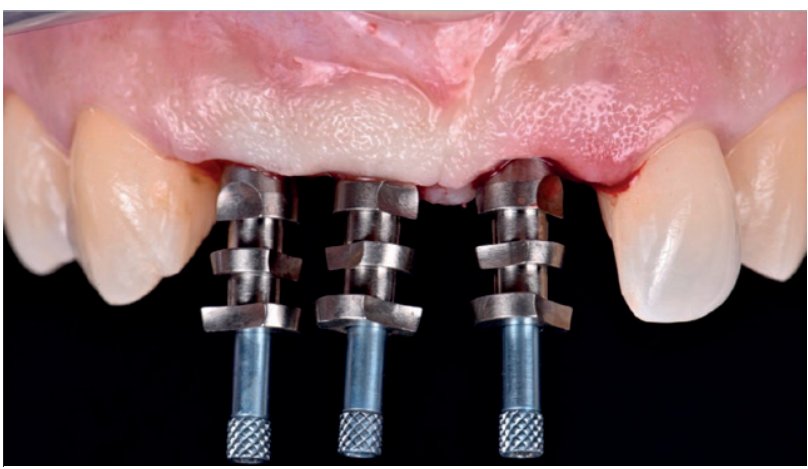

Figure 27 First implant impression (four months later)

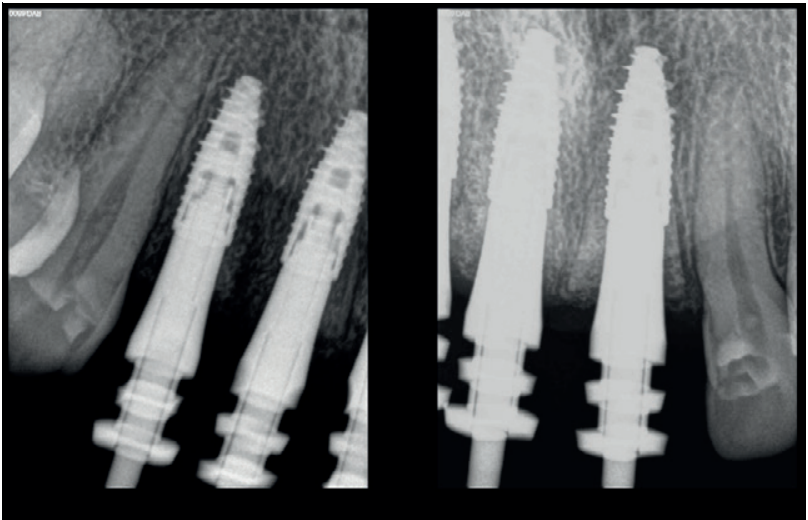

Figure 28 X-ray transfer impression

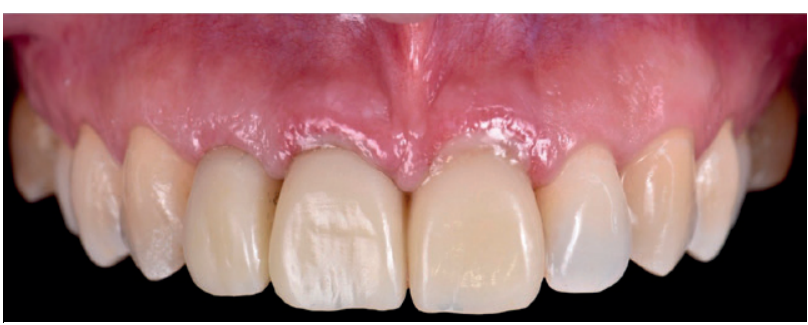

Figure 29 First loaded provisionals (four months later) were doing pressure on selected zones to modulate gingival contour 
tissue around the implants (Figure 25, $26,27,28,29,30$ ).

Two months later the soft tissue was stable (Figure 31, 32) and the final impression was done, copying the subcritical and critical contour of the provisionals (Figure 33).

Final prosthodontic treatment was finished with screwed crowns in zirconia and stratificated ceramic (Figure 34, 35).

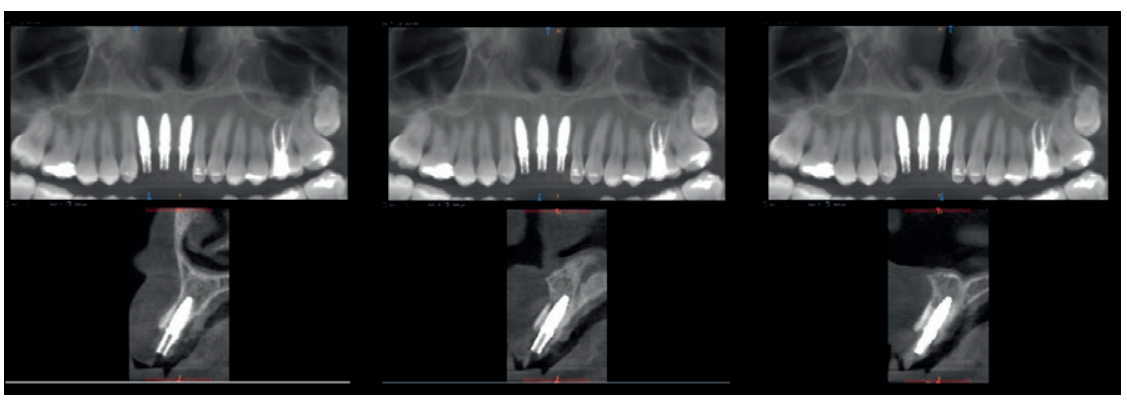

Figure $30 \mathrm{CBCT}$ : First loaded provisionals (four months later)

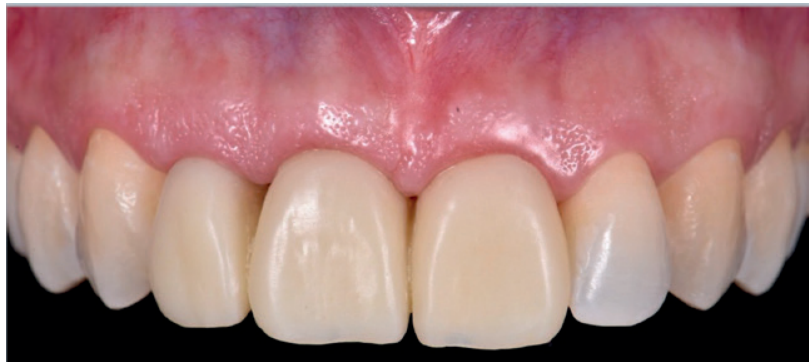

Figure 31 Follow-up five months later in frontal view

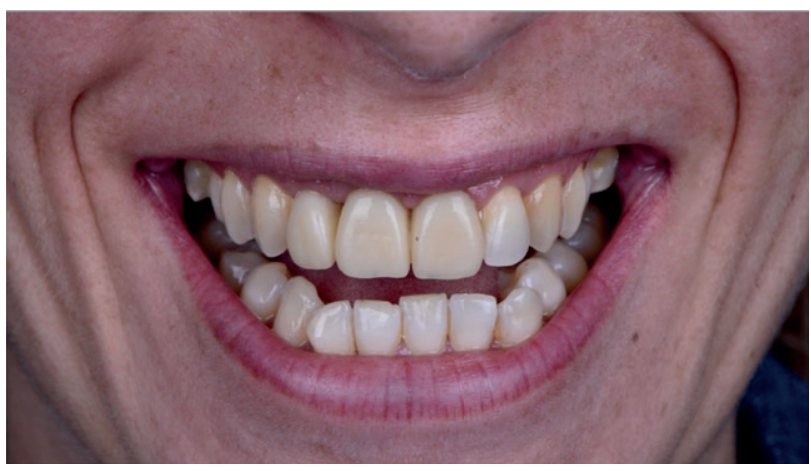

Figure 32 Follow-up five months later

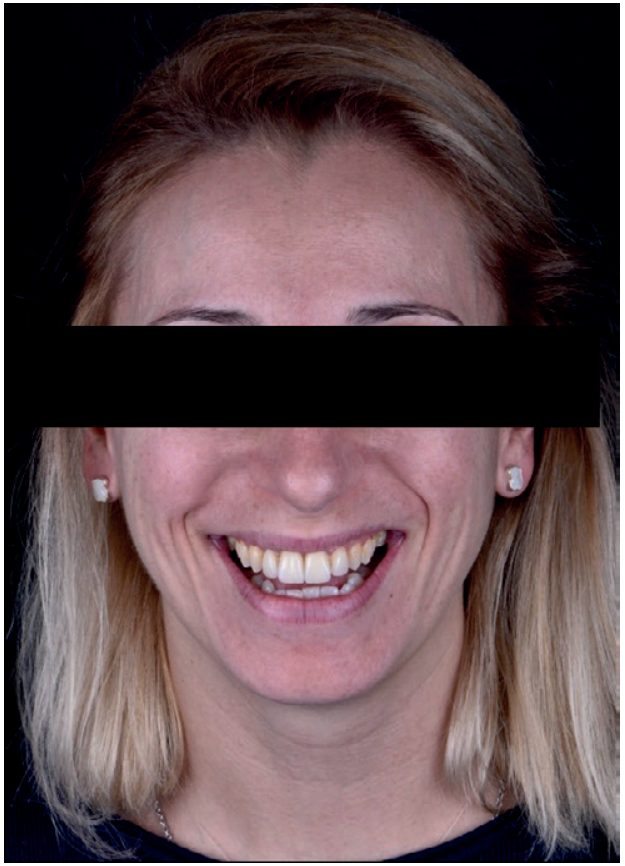

Figure 34 Final extra-oral frontal view

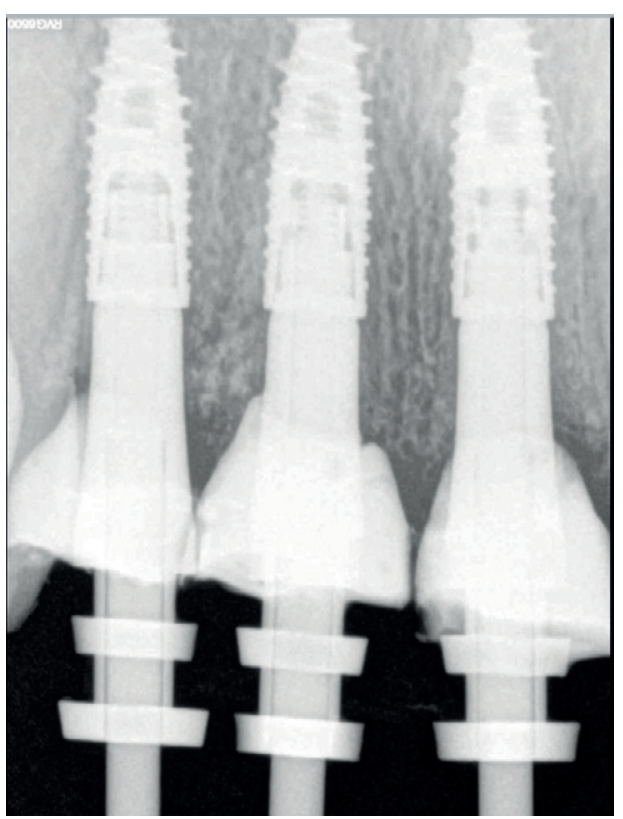

Figure 33 Final Impression (six months later): duplicate the subcritical and critical contour

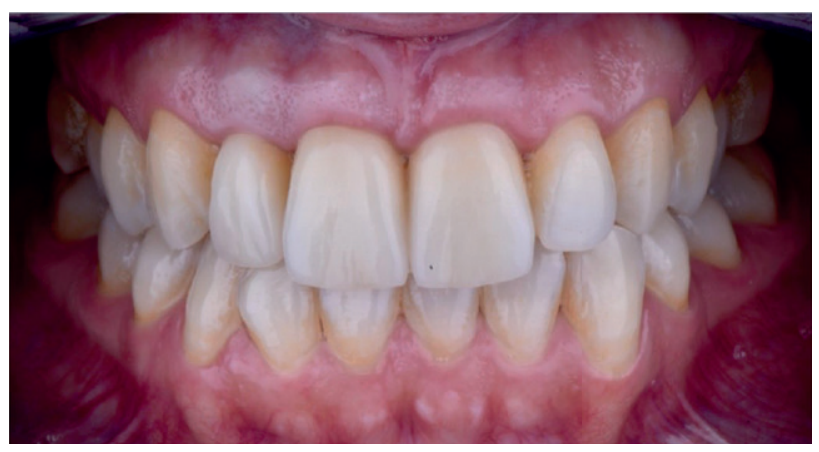

Figure 35 Final intra-oral frontal view in occlusion 


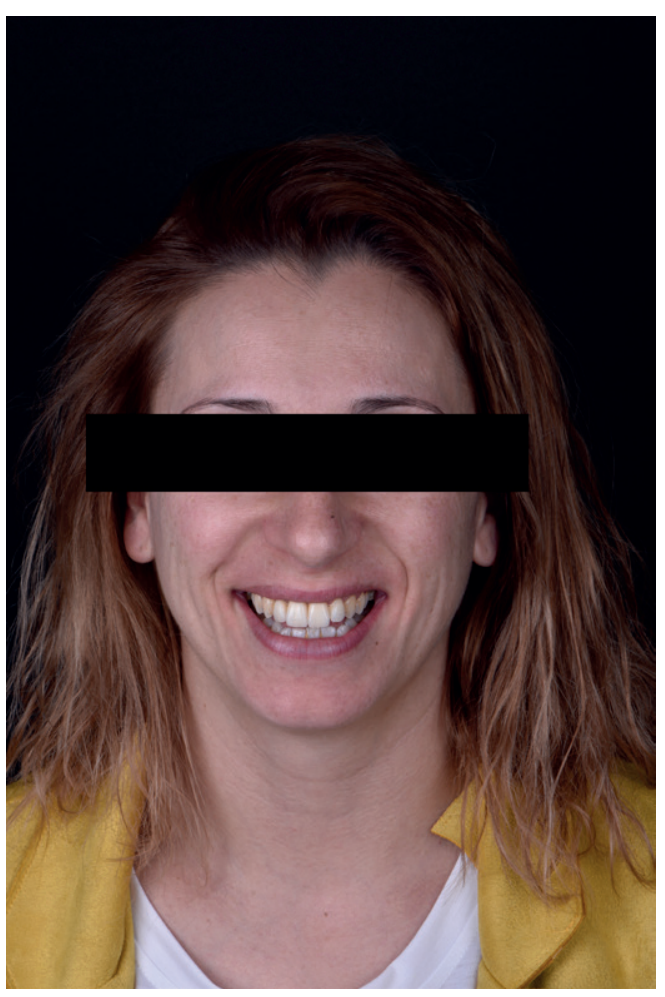

Figure 36 Follow-up four months later final rehabilitation in frontal view

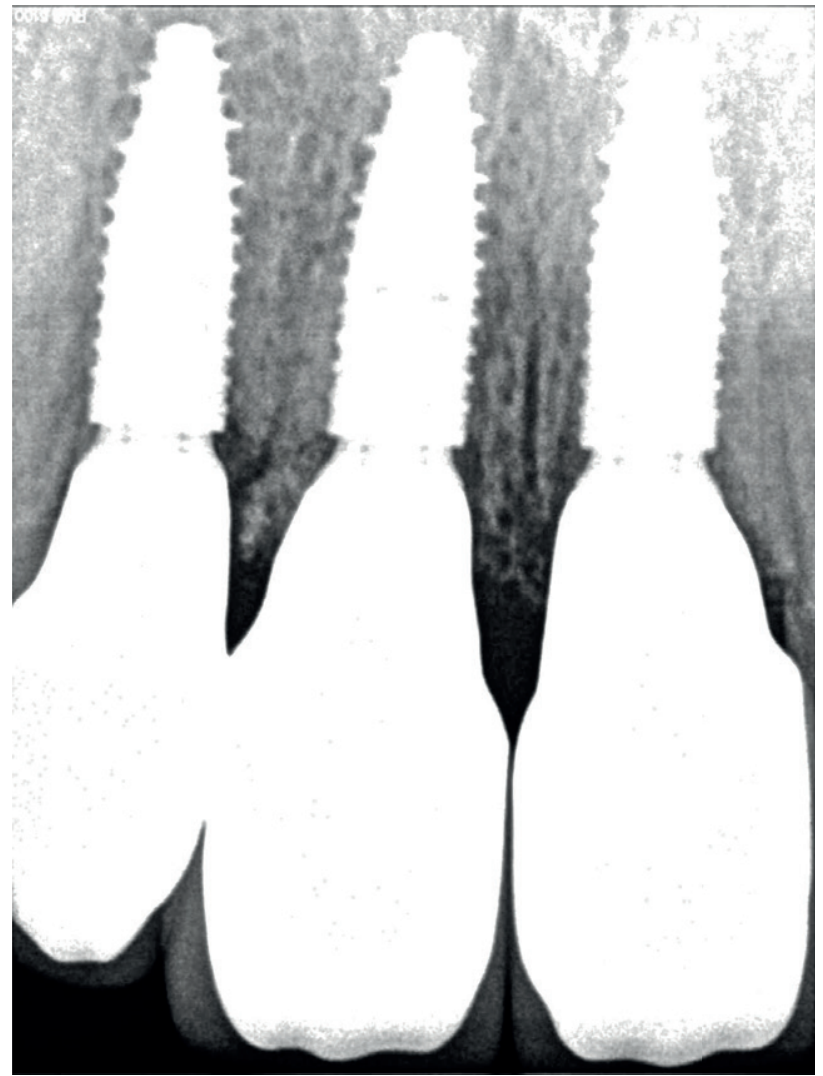

Figure 37 Follow-up radiographic (periapical) four months later final rehabilitation

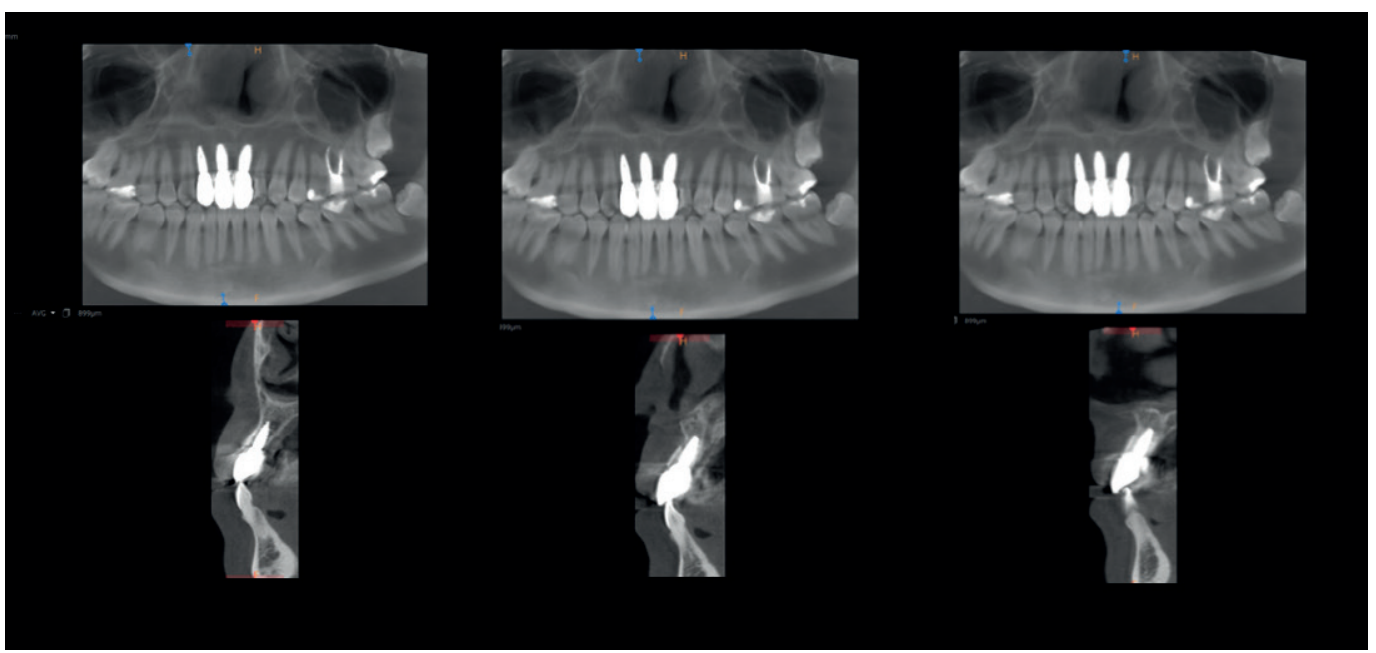

Figure 38 Follow-up radiographic (CBCT) four months later final rehabilitation

At the clinical control appointment (four months later) the gingival contour was well-preserved and no recession was observed. Gingival papillaes were observed in all triangles. No inflammatory signs were detected on the periodontal tissue (Figure 36).

CBCT indicated that the marginal bone level around implant was stable in both vertical and horizontal directions (Figure 37, 38).

\section{DISCUSSION}

The periodontium is an important structure that supports the tooth and is affected by any changes that the tooth may undergo, including extraction. The shape and volume of the alveolar process is influenced by the presence and the absence of teeth (Tallgren 1972), as well as the direction of eruption of the tooth
(Marks 1995; Marks \& Schroeder 1996). Tooth extraction results in gingival tissues that undergo atrophy, with the complete loss of attachment apparatus including cementum, periodontal ligament fibres and bundle bone. ${ }^{14}$

The guided bone regeneration (GBR) procedures could prevent the volume changes. ${ }^{8}$ However, the soft tissue volume contraction is often related to this surgical procedure, often resulting in a volumetric reduction of about $30 \%$, which leads to unsatisfactory results specially in aesthetic areas. ${ }^{15}$

Retention of the root may modify the physiological changes seen in extraction sockets. Decoronated roots, either vital or endontically treated, such as the root submergence technique (Salama 2007) ${ }^{16}$ and Socket-Shield (Hurzeler 2010) ${ }^{9}$, can preserve the alveolar bone at an extraction site. 8,17 These techniques use 
the patient's tooth tissues and periodontium to preserve the alveolar ridge and limit postextraction resorption. ${ }^{18}$

Hurzeler et al (2010) introduced for the first time the "SocketShield technique" experimented on an animal model and then on humans. ${ }^{9}$ The idea is to maintain the periodontium and the crestal bone at the original level by leaving part of the root portion on the buccal side during the immediate implant. ${ }^{15}$

Histological studies performed on animal model demonstrated that the retaining of the vestibular root portion, treated or not with enamel matrix derivate (Emdogain', Straumann", Basel, Switzerland), creates a layer of so-called "new cementum" between the fragment and the implant positioned immediately 15,17

Moreover, no bone remodeling on the buccal side was observed after 4 months of healing. ${ }^{19}$

This technique consists in the sectioning and removal of the crown of the compromised, nonrestorable tooth, leaving only the root. Each one is sectioned into 2 parts, mesiodistally.

The palatal root portion is gently and atraumatically extracted, taking care not to damage or mobilize the buccal portion of the root.

This portion of the root, in contact with the buccal bone, is left in situ after being reduced in thickness (to assume a concave shape similar to the profile of the bone crest) and in height (up to $1 \mathrm{~mm}$ above the bone ridge). Recently studies have advocated that fragment should be bone level or $1 \mathrm{~mm}$ below to avoid the most common complication, exposure of the fragment. $2,8,10,18,19$ In this report, to correct the high line smile and zenith, an osteotomy on the teeth $21,11,12(1 \mathrm{~mm})$ and a gengivectomy $(1 \mathrm{~mm})$ on tooth 13 were performed.

In relation to the thickness of the fragment, the absortion may decrease if the thickness of the root fragment increases, when the thickness of the root plate is in the $0.5-1.5 \mathrm{~mm}$ range. This is justified by the heating and vibration on tooth preparation and instability of thinner fragments. ${ }^{3}$ In this case it was observed a type I socket. These are the most predictable sockets to treat. Most of the implantology cases seen demonstrating excellent results are type I sockets. ${ }^{11}$

All treatment was performed under magnification (3.8 ExamVision Galileo HD Magnifiers ). The current authors strongly recommend meticulous reduction of the socket-shield to the bone crest, achievable almost exclusively with reflection of the coronal gingiva under magnification. Because of the risk of tissue loss, a full-thickness flap is not recommended in most patients, especially in aesthetic zone sites. ${ }^{20}$

Gluckman et $a^{21,22}$, suggest that, if present, the gap between the implant and the buccal portion of the root should always be grafted with particulate grafting material. By contrast, Siormpas and Mitsias ${ }^{23,24}$ suggest that it is not necessary to graft the space between the residual buccal root portion and the implant. ${ }^{1}$ Hurzeler's ${ }^{9}$ studies refer that the positioning of heterologous graft material between the root portion and the implant is necessary, without using chemical agents for conditioning of the inner root surface.

It is important to fill the gap between the implant and alveolar socket with slow-resorbable biomaterial to prevent bone resorption after tooth extraction. ${ }^{25}$ The healing process is accelerated by socket closure and soft tissue maturation. ${ }^{13,15,26}$
According to Huang $2017^{10}$ the gap between tooth fragment and implant should be at least $2 \mathrm{~mm}$ to provide proper space for implant and the bone materials.

The Socket-Shield's indications are vertical fracture of teeth without pulp pathologies, non-restorable asymptomatic teeth with healthy and stable buccal root, teeth with healthy gingival tissue, adequate amount of bone volume apical to the extraction socket to support implant.1,13

Contraindications of this technique include infection, fracture (absent buccal lamina which develops for instance after vertical root fractures or periodontitis), internal or external resorption, past or present periodontal disease, mobility or widening of the periodontal ligament, poor quality of bone, inadequate soft tissue around the socket. ${ }^{1,2,13}$

The provisional rehabilitation was performed with a structure bonded on the adjacent teeth avoiding the risks of doing immediate loading in an aesthetic zone and promoting the sealing.

After 4 months when osteoingration was complete it was possible to move for the second surgery. ${ }^{27}$ Flapless surgery guaranteed the blood supply of the buccal plate of the ridge and preserved the stability of the fragment and the soft tissue. ${ }^{10,18}$

After second surgery, loaded provisional was made to manage the peri-implant soft tissue. Through the relief and pressure zones of the provisionals it was possible to manipulate the collapsed soft tissue caused by the osteotomy.

In this report, three implants side by side in a aesthetic zone is a demanding case to create a gingival contour with papillae. Implants should have a distance of at least $3 \mathrm{~mm}$ to prevent the loss of the interproximal bone peak and Tarnow showed that the expected height of the papilla between two implants is around $3.4 \mathrm{~mm} .{ }^{28,29}$

Two months later impressions were taken for the final prosthodontics performed with the same subcritical and critical contour (duplicated at the time of the final impression).

The preparation of the prosthetic emergence profile reflects an S-shape. This prosthetic design provides maximal soft tissue infill and avoids excessive pressure on the socket-shield's coronal portion. ${ }^{18,30}$

Retaining the buccal aspect of the root seems to preserve the bundle bone. In this case report, it was demonstrated that the Socket-Shield technique with immediate implant placement may be beneficial in preserving buccal bone plate and healthy peri implant tissues can be observed. ${ }^{9}$

\section{CONCLUSIONS}

In this report, modified Socket-Shield technique was combined with xenograft bone filling the gap between the shield and the immediate implant. The implant site was successful in maintaining peri-implant tissue. The final implant-supported prostheses exhibited no significant gingival contour recession and showed proper function. The Socket-Shield technique prevents the recession of buccofacial tissue to an immediately placed implant in the aesthetic area. Moreover, xenograft bone maintains the three-dimensional volume of the socket.

Funding: No funding sources

Conflict of interest: None declared 


\section{REFERENCES}

1. Han CH, Park KB, Mangano FG. The Modified Socket Shield Technique. J Craniofac Surg. 2018 Nov;29(8):2247-2254.

2. Gluckman H, Salama M, Du Toit J. A retrospective evaluation of 128 socket-shield cases in the esthetic zone and posterior sites: Partial extraction therapy with up to 4 years follow-up. Clin Implant Dent Relat Res. 2017;00:1-8.

3. Tan Z, Kang J, Liu W, Wang H. The effect of the heights and thicknesses of the remaining root segments on buccal bone resorption in the socket-shield technique: An experimental study in dogs. Clin Implant Dent Relat Res. 2018 Feb 8.

4. Hurzeler MB, Zuhr O, Schupbach P, Rebele SF, Emmanouilidis N, FickI S. The Socket-Shield technique: a proof-of-principle report. J Clin Periodontol $2010 ; 37: 855$-862.

5. Araujo MG, Silva CO, Misawa M, Sukekava F. Periodontol 2000. 2015 Jun;68(1):122-34.

6. Guo T, Nie R, Xin X, Wang H, Qi M, Yu K, Wang Y, Du L, Zhou Y. Tissue preservation through socket-shield technique and platelet-rich fibrin in immediate implant placement: A case report. Medicine (Baltimore). 2018 Dec; 97(50):e13175.

7. Botticelli D, Berglundh T, \& Lindhe J. Hard-tissue alterations following immediate implant placement in extraction sites. J Clin Periodontol. 2004 ; 31 : 820-828.

8. Gluckman H, Salama M, Du Toit J. Partial Extraction Therapies (PET) Part 2: Procedures and Technical Aspects. Int J Periodontics Restorative Dent. 2017 May/ Jun;37(3):377-385.

9. Hürzeler MB, Zuhr O, Schupbach P, et al. The socket-shield technique: a proof-of-principle report. J Clin Periodontol 2010;37:855-862

10. Huang H, Shu L, Liu Y, Wang L, Li J, Fu G. Immediate Implant Combined With Modified Socket-Shield Technique: A Case Letter.J Oral Implantol. 2017 Apr;43(2):139-143.

11. Elian N, Cho SC, Froum S, Smith RB, Tarnow DP. A simplified socket classification and repair technique. Pract Proced Aesthet Dent. 2007 Mar;19(2):99-104;

12. Otto Zuhr, Marc H, rzeler. Plastic-Esthetic Periodontal and Implant Surgery. Quintessence. 2012.

13. Bathla S, Fry R, Goyal K, Goyal S, Talnia S. Socket shield technique for immediate implant placement. IP Int J Periodontol Implantol 2018;3(3):87-90.

14. Tan WL, Wong TL, Wong MC, Lang NP. A systematic review of post-extractional alveolar hard and soft tissue dimensional changes in humans. Clin Oral Implants Res 2012: 23 (Suppl 5): 1-21.

15. Bramanti E, Norcia A, Cicci ` M, Matacena G, Cervino G, Troiano G, Zhurakivska K, Laino Postextraction Dental Implant in the Aesthetic Zone, Socket Shield Technique Versus Conventional Protocol. J Craniofac Surg. 2018 Jun;29(4):1037-1041

16. Salama M, Ishikawa T, Salama H, Funato A, Garber D. Advantages of the root submergence technique for Pontic site development in esthetic implant therapy. Int J Periodontics Restorative Dent 2007; 27: 521-527.

17. Gharpure AS, Bhatavadekar NB. Current Evidence on the Socket-Shield Technique: A Systematic Review. J Oral Implantol. 2017 Oct;43(5):395-403.

18. Gluckman H, Nagy K, Du Toit J. Prosthetic management of implants placed with the socket-shield technique.J Prosthet Dent. 2019 Apr;121(4):581-585.

19. Baumer D, Zuhr O, Rebele S, et al. The socket-shield technique: first histological, clinical, and volumetrical observations after separation of the buccal tooth segment-a pilot study. Clin Implant Dent Relat Res. 2015;17:71-82.

20. Glocker M, Attin T, Schmidlin P.R. Schmidlin. Ridge Preservation with Modified Socket-Shield Technique: A Methodological Case Series. Dent. J. 2014 Jan $23 ; 2,11-21$.

21. Gluckman H, Salama M, Du Toit J. Partial extraction therapies (PET) part 1: maintaining alveolar ridge contour at pontic and immediate implant sites. Int J Periodontics Restorative Dent. 2016;36:681-687

22. Gluckman H, Salama M, Du Toit J. Partial extraction therapies (PET) part 2: procedures and tecnical aspects. Int J Periodontics Restorative. Dent 2017;37:377-385

23. Siormpas KD, Mitsias ME, Kontsiotou-Siormpa E, et al. Immediate implant placement in the esthetic zone utilizing the "root-membrane" technique: clinical results up to 5 years post-loading. Int J Oral.Maxillofac Implants 2014;29:1397-1405

24. Mitsias ME, Siormpas KD, Kontsiotou-Siormpa E, et al. A step-by-step description of PDL-mediated ridge preservation for immediate implant rehabilitation in the esthetic region. Int J Periodontics Restorative Dent. 2015;35:835-841

25. Kan JYK, Rungcharassaeng K, Deflorian M, Weinstein T, Wang HL, Testori T. Immediate implant placement and provisionalization of maxillary anterior single implants. Periodontol 2000. 2018 Jun;77(1):197-212.

26. Araujo MG, Lindhe J. Socket grafting with the use of autologous bone: an experimental study in the dog. Clin. Oral Impl. Res. 22, 2011; 9-13.

27. Quirynen M, Assche N.V, Botticelli D, Berglundht. How does the timing of implant placement to extraction affect outcome. Int j oral maxillofac implants 2007;22(SUPPL): 203-223.

28. Tarnow DP, Cho SC, Wallace SS. The effect of inter-implant distance on the height of the inter-implant bone crest. J Periodontal 2000; 71: 546-549.

29. Tarnow D, Elian N, Fletcher P, Froum S, Magner A, Cho SC, Salama M, Salama H, Garber DA. Vertical distance from the crest of bone to the height of the interproximal papilla between adjacent implants. J Periodontol. 2003 Dec;74(12):1785-8.

30. Su H, Gonzalez-Martin O, Weisgold A, Lee E. Considerations of Implant Abutment and Crown Contour: Critical Contour and Subcritical Contour. Int J Periodontics Restorative Dent. 2010 Aug;30(4):335-43. 